\title{
Níveis de proteína bruta em suplementos multiplos para novilhas Nelore em pastejo na época seca
}

\section{Levels of crude protein in multiple supplements for Nelore heifers on pasture in the dry season}

\author{
Leandro Soares Martins ${ }^{1 *}$; Mário Fonseca Paulino; Marcos Inácio Marcondes ${ }^{2}$; \\ Luciana Navajas Rennó ${ }^{2}$, Daniel Mageste de Almeida ${ }^{1}$; Lívia Vieira de Barros ${ }^{3}$; \\ Aline Gomes da Silva ${ }^{1}$; Victor Valério de Carvalho ${ }^{1}$; Sidnei Antônio Lopes ${ }^{1}$; \\ Josilaine Aparecida da Costa Lima'; Felipe Henrique de Moura ${ }^{4}$
}

\section{Resumo}

Avaliou-se o efeito de níveis de proteína bruta em suplementos sobre o desempenho, consumo, digestibilidade e eficiência microbiana. Foram utilizadas 40 novilhas Nelore, com idade inicial média de oito meses e peso inicial médio de $230 \pm 3,39 \mathrm{~kg}$. Os suplementos avaliados foram: mistura mineral fornecida ad libitum (MM), suplementos contendo 10\%, 20\%, 30\% e 40\% de proteína bruta (PB), constituindo os tratamentos $\mathrm{PB}_{10}, \mathrm{~PB}_{20}, \mathrm{~PB}_{30}, \mathrm{~PB}_{40}$, respectivamente. Observou-se maior peso corporal final (PCF) e ganho médio diário de peso (GMD) nos animais suplementados em relação aos não suplementados $(\mathrm{P}<0,10)$. Os consumos de todos os nutrientes foram maiores $(\mathrm{P}<0,10)$ nos animais suplementados em relação aos não suplementados. O consumo de proteína bruta apresentou efeito linear crescente, com o aumento dos níveis de PB nos suplementos. Observou-se efeito quadrático na digestibilidade da PB com o aumento dos níveis de PB nos suplementos. A produção de nitrogênio microbiano (Nmic), nitrogênio ureico no soro (NUS) e a relação nitrogênio ureico na urina/nitrogênio da creatinina (NUU/Ncre) foram maiores $(\mathrm{P}<0,10)$ em animais suplementados. Observou-se efeito quadrático sobre a produção de Nmic, eficiência microbiana (Emic), NUS e NUU/Ncre com o aumento dos níveis de $\mathrm{PB}$ nos suplementos múltiplos. A suplementação múltipla proporciona maiores ganhos de peso e peso corporal final no período pós desmama de novilhas Nelore.

Palavras-chave: Desempenho, forragem de baixa qualidade, nitrogênio, suplementação

\begin{abstract}
It was evaluated the effect of levels of crude protein supplement on performance, intake, digestibility and microbial efficiency. Forty Nelore heifers, with an initial average age of eight months and an initial average weight of $230 \pm 3,39 \mathrm{~kg}$, were used. The evaluated supplements were: mineral mix provided ad libitum (MM), supplements containing 10\%, 20\%, 30\% and $40 \%$ crude protein $(\mathrm{CP})$, representing the treatments $\mathrm{PB}_{10}, \mathrm{~PB}_{20}, \mathrm{~PB}_{30}, \mathrm{~PB}_{40}$, respectively. It was observed a higher final body weight and weight gain for supplemented animals compared to non-supplemented $(\mathrm{P}<0.10)$. The intake of all nutrients were higher $(\mathrm{P}<0.10)$ for supplemented animals compared to non-supplemented. The crude protein

\footnotetext{
Discentes do Programa de Pós Graduação, Dept ${ }^{\circ}$ de Zootecnia da Universidade Federal de Viçosa, DZO/UFV, Viçosa, MG. E-mail: leandros_martins@yahoo.com.br; danielmagestedealmeida@hotmail.com; alinegomesdasilva@rocketmail.com; victorvaleriomg@hotmail.com; sidneyufv@hotmail.com; josilaine.lima@ufv.br

2 Profs. Doutores, Dept ${ }^{\circ}$ de Zootecnia, DZO/UFV, Viçosa, MG. E-mail: mpaulino@ufv.br; marcos.marcondes@ufv.br; lucianarenno@ufv.br

3 Profa, Universidade Federal do Mato Grosso, UFMT, Cuiabá, MT. E-mail: liviavieiradebarros@gmail.com

4 Discente de graduação do Curso de Zootecnia, Dept ${ }^{\circ}$ de Zootecnia, DZO/UFV, Viçosa, MG. E-mail: felipe.moura@ufv.br

* Autor para correspondência
} 
intake had increased linearly with increasing levels of $\mathrm{CP}$ in supplements. The digestibility of DM, OM, $\mathrm{CP}$ and TDN were higher $(\mathrm{P}<0.10)$ in supplemented animals compared to non-supplemented. There was a quadratic effect on $\mathrm{CP}$ digestibility with increased levels of $\mathrm{CP}$ in supplements. The production of microbial nitrogen ( $\mathrm{N} \mathrm{mic}$ ), serum urea nitrogen (NUS) and reason urea nitrogen in the urine/creatinine nitrogen (NUU/Ncre) were higher $(\mathrm{P}<0.10)$ for supplemented animals. Quadratic effect was observed on production of Nmic, microbial efficiency (Emic), NUS and NUU/Ncre with increased levels of CP in multiple supplements. The multiple supplementation provides higher weight gain and final body weight in the period after weaning from Nellore females.

Key words: Low quality forage, nitrogen, performance, supplementation

\section{Introdução}

Para o sucesso no sistema de produção de bovinos de corte é preciso que haja um eficiente controle reprodutivo do rebanho, principalmente das fêmeas. Para isso é necessário que essas cresçam de forma contínua desde o nascimento até a fase de reprodução, permitindo a antecipação da fase reprodutiva e consequentemente maior taxa de reposição, o que proporciona uma maior pressão de seleção no rebanho, tornando-o cada vez mais produtivo e rentável.

$\mathrm{O}$ rebanho brasileiro é composto historicamente por cerca de $80 \%$ de animais zebuínos (FAO, 2005), os quais geralmente apresentam uma menor precocidade sexual quando comparados a animais de raças taurinas. Isso ocorre principalmente devido a duas limitações: genética e nutricional.

Em relação a genética, o trabalho realizado por Eler et al. (2002) permitiu concluir que a característica probabilidade de prenhez aos 14 meses (PP14), apresentou herdabilidade de 57\% em animais Nelore, tornando viável a seleção baseada nessa característica.

Nutricionalmente ocorrem deficiências múltiplas em animais criados exclusivamente a pasto. Para contornar esse problema, a melhor forma é oferecer aos animais uma suplementação múltipla, sempre aliada ao fornecimento de 4 a $6 \%$ do peso corporal dos animais em matéria seca potencialmente digestível de forragem (PAULINO et al., 2008).
Apesar do suplemento a ser oferecido ser múltiplo, é importante que ele apresente teores mais altos de proteína, pois esse é normalmente considerado o nutriente limitante no caso de forrageiras tropicais, especialmente na época seca do ano. As limitações inerentes aos recursos nutricionais basais de baixa qualidade são intrinsecamente limitações ao crescimento microbiano no rúmen (DETMANN; PAULINO; VALADARES FILHO, 2010). Nestas situações, devido à alta relação carbono: nitrogênio no substrato basal haverá deficiência de compostos nitrogenados para síntese de enzimas microbianas, as quais são responsáveis pela degradação dos compostos fibrosos insolúveis da forragem (DETMANN et al., 2009). Assim sendo, é importante o suprimento adequado de proteína para os animais em produção, para que esses possam apresentar adequado desempenho, tornando o sistema de produção de carne mais eficiente.

A proteína é de grande importância para o metabolismo animal e consequentemente para o desempenho, porém pouco se sabe a respeito dos níveis adequados de proteína bruta que os suplementos destinados a fêmeas recémdesmamadas em pastejo devem apresentar, uma vez que há carência de informações acerca de exigências nutricionais para novilhas Nelore em sistema de pastejo. Objetivou-se ao realizar este experimento, determinar o nível de proteína bruta mais adequada em suplementos múltiplos, para novilhas Nelore em pastejo. 


\section{Material e Métodos}

Animais, delineamento experimental e suplementos

O experimento foi conduzido no Setor de Bovinocultura de Corte da Universidade Federal de Viçosa, Viçosa-MG $\left(20^{\circ} 45^{\prime}\right.$ S e $\left.42^{\circ} 52^{\prime} \mathrm{W}\right)$, entre os meses de Junho a Setembro de 2011, referente ao período de seca. A área experimental está localizada em região montanhosa com $670 \mathrm{~m}$ de altitude e com precipitação média de $1300 \mathrm{~mm}$ anuais. O experimento teve duração de 84 dias divididos em três períodos com 28 dias cada.

Foram utilizadas 40 novilhas Nelore, filhas de touros selecionados para a característica probabilidade de prenhez aos 14 meses (PP14), com idade e pesos médios iniciais de oito meses e $230 \pm 3,39 \mathrm{~kg}$, respectivamente. Foi destinada aos animais uma área experimental com 12,5 hectares, sendo esta constituída por cinco piquetes de 2,5 ha, formados uniformemente pela gramínea Brachiaria decumbens Stapf., providos de bebedouros e cochos, sendo estes cobertos e com acesso pelos dois lados.

O delineamento experimental foi o inteiramente casualizado, com cinco tratamentos (suplementos) e com oito repetições. Foram avaliados quatro suplementos (Tabela 1) com diferentes níveis de proteína bruta. Os níveis de proteína bruta avaliados foram 10; 20; 30 e $40 \%$ para os tratamentos $\mathrm{PB}_{10}$, $\mathrm{PB}_{20}, \mathrm{~PB}_{30}$ e $\mathrm{PB}_{40}$, respectivamente, mais um grupo controle (MM) no qual os animais receberam apenas mistura mineral ad libitum. Os suplementos foram fornecidos na quantidade de 1,0 kg por animal por dia, próximo às 10 horas da manhã.

Tabela 1. Composição percentual dos suplementos com base na matéria natural.

\begin{tabular}{cccccc}
\hline & \multicolumn{5}{c}{ Suplementos } \\
\hline Ingredientes & $\mathrm{MM}^{2}$ & $\mathrm{~PB}_{10}{ }^{2}$ & $\mathrm{~PB}_{20}{ }^{2}$ & $\mathrm{~PB}_{30}{ }^{2}$ & $\mathrm{~PB}_{40}{ }^{2}$ \\
\hline Mistura Mineral & 100 & 3,0 & 3,0 & 3,0 & 3,0 \\
Grão de sorgo moído & --- & 47 & 33,0 & 19,0 & 5,0 \\
Grão de milho moído & --- & 47 & 33,0 & 19,0 & 5,0 \\
Farelo de Soja & --- & 3,0 & 31,0 & 59,0 & 87,0 \\
& & & & & \\
\hline PB (\%MS) & --- & 9,2 & 19,2 & 29,3 & 39,5 \\
\hline
\end{tabular}

${ }^{1}$ Composição percentual: fosfato bicálcico, 50,00; cloreto de sódio, 47,775; sulfato de zinco, 1,4; sulfato de cobre, 0,7; sulfato de cobalto, 0,05; iodato de potássio, 0,05 e sulfato de magnésio: 0,025. ${ }^{2}$ mistura mineral (MM), suplementos com $10 \%\left(\mathrm{~PB}_{10}\right)$, $20 \%\left(\mathrm{~PB}_{20}\right), 30 \%\left(\mathrm{~PB}_{30}\right)$ e $40 \%$ de proteína bruta $\left(\mathrm{PB}_{40}\right)$.

Fonte: Elaboração dos autores.

Ao início do experimento, todos os animais foram submetidos ao controle de ecto e endoparasitas e durante o período experimental, quando necessário. A cada sete dias os animais foram rotacionados entre os piquetes, visando o controle de possíveis efeitos de piquetes sobre os suplementos.

O ganho médio diário (GMD) de peso das novilhas foi estimado pela diferença entre o peso corporal final e o inicial, ambos após jejum hídrico e de alimentos por 14 horas, dividido pelo número de dias experimentais, incluindo o período do ensaio para avaliação do consumo e digestibilidade.

\section{Procedimentos experimentais e amostragem}

A amostragem para avaliação qualitativa da forragem consumida pelos animais foi realizada via simulação manual de pastejo a cada 14 dias, realizada pela mesma pessoa durante todo o período experimental, caminhando em "zig-zag" pelos piquetes. Essa amostra foi pesada e levada imediatamente à estufa com circulação forçada de ar a $60^{\circ} \mathrm{C}$ por 72 horas e moída em moinho de facas (1 e $2 \mathrm{~mm}$ ). 
No décimo quinto dia de cada período experimental foi realizada coleta de forragem para quantificação da massa de matéria seca e de matéria seca potencialmente digestível (MSpd), através do corte rente ao solo de quatro áreas delimitadas por um quadrado metálico de $0,5 \times 0,5 \mathrm{~m}$, selecionados aleatoriamente em cada piquete. Essa amostra também foi pesada e levada imediatamente à estufa com circulação forçada de ar a $60^{\circ} \mathrm{C}$ por 72 horas.

A MSpd foi estimada segundo Paulino et al. (2008):

$$
\mathrm{MSpd}=0,98 \times(100-\mathrm{FDNcp})+(\mathrm{FDNcp}-\mathrm{FDNi})
$$

Para a avaliação das características nutricionais das novilhas, a partir do $42^{\circ}$ dia do período experimental foi realizado um ensaio de digestibilidade com duração de nove dias. Utilizouse o método de três indicadores. Para estimar a excreção fecal, foi fornecido aos animais o indicador externo óxido crômico $\left(\mathrm{Cr}_{2} \mathrm{O}_{3}\right)$ (DETMANN et al., 2001), colocado em cartuchos de papel, correspondente a $15 \mathrm{~g}$ por novilha/dia, aplicado com auxílio de uma sonda metálica diretamente no esôfago, às 10:00 horas. Para estimar o consumo individual de suplemento foi utilizado o dióxido de titânio $\left(\mathrm{TiO}_{2}\right)$ fornecido via suplemento (Titgemeyer et al., 2001) na proporção de $10 \mathrm{~g}$ de indicador $/ \mathrm{kg}$ de suplemento. Para estimar o consumo de MS de pasto foi utilizado como indicador interno a fibra em detergente neutro indigestível (FDNi) (DETMANN et al., 2001).

Dos nove dias do ensaio, os seis primeiros foram destinados à adaptação ao $\mathrm{Cr}_{2} \mathrm{O}_{3}$ e ao $\mathrm{TiO}_{2}$. Nos últimos três dias $\left(48^{\circ}, 49^{\circ}\right.$ e $50^{\circ}$ dias $)$ foram realizadas coletas de fezes em horários diferenciados, às 15 , 11 e às 7 horas, respectivamente, objetivando obter uma amostra composta que representasse o que o animal defecava durante o dia. As amostras de fezes foram coletadas imediatamente após a defecação ou diretamente no reto dos animais, em quantidades aproximadas de $200 \mathrm{~g}$, sendo identificadas por animal e secas em estufa com circulação forçada de ar $\left(60^{\circ} \mathrm{C} / 72\right.$ horas $)$. Após a secagem, foram moídas em moinho de facas (1e $2 \mathrm{~mm}$ ).
No quinto dia do ensaio ( $46^{0}$ dia experimental) foi realizada uma simulação manual de pastejo, em cada piquete separadamente, sendo estas amostras usadas para a estimação do consumo e dos coeficientes de digestibilidade.

No último dia do ensaio, para estimativa de consumo e digestibilidade, foram obtidas amostras "spot" de urina, em micção espontânea e de sangue, via punção da veia jugular, realizadas quatro horas após o fornecimento do suplemento. Após a coleta, as amostras de urina foram diluídas em $\mathrm{H}_{2} \mathrm{SO}_{4}(0,036 \mathrm{~N})$ e congeladas a $-20^{\circ} \mathrm{C}$ para posterior avaliação dos teores de creatinina, ureia e derivados de purina. As amostras de sangue foram coletadas neste mesmo dia, utilizando-se de tubos de vácuo com ativador de coágulo e gel separador (BD Vacuntainer ${ }^{\circledR}$, SST II Advance). O sangue foi imediatamente centrifugado a $2700 \times \mathrm{g}$ por 15 minutos sendo o soro armazenado $\mathrm{a}-20^{\circ} \mathrm{C}$.

\section{Análises químicas}

Nas amostras de forragem obtidas via simulação manual do pastejo e dos concentrados foram quantificados os teores de matéria seca (MS); matéria mineral (MM); proteína bruta (PB), extrato etéreo (EE), segundo Silva e Queiroz (2002); fibra em detergente neutro (FDNcp), segundo Mertens (2002), utilizando-se $\alpha$-amilase termoestável e omitindo-se o uso de sulfito de sódio, foram realizadas correções para proteína e cinzas na FDN, quantificou-se o teor de nitrogênio insolúvel em detergente neutro (NIDN) seguindo as recomendações de Van Soest e Robertson (1985), com correções para cinzas; fibra em detergente neutro indigestível (FDNi), de acordo com Valente et al. (2011b), obtida após a incubação em sacos (F57 Ankom ${ }^{\circledR}$ ) in situ por 288 horas. Nas amostras de forragem destinadas ao cálculo da massa de MS e MSpd foram quantificados os teores de MS; FDNcp e FDNi, conforme descrito anteriormente.

Os carboidratos não fibrosos dos suplementos foram quantificados segundo Weiss (1999), utilizando-se a seguinte equação: 
$\mathrm{CNFcp}=100-(\% \mathrm{~PB}+\% \mathrm{FDNcp}+\% \mathrm{EE}+\% \mathrm{de}$ cinzas)

Foi elaborada uma amostra composta de fezes após a secagem na estufa de circulação forçada de ar a $60^{\circ} \mathrm{C}$, para cada animal, dos três dias de coleta. As amostras foram armazenadas em potes plásticos, devidamente identificados e posteriormente analisadas quanto aos teores de cromo, por espectrofotometria de absorção atômica (WILLIANS; DAVID; IISMA, 1962) e quanto aos teores de dióxido de titânio, por colorimetria (TITGEMEYER et al., 2001). Avaliaram-se também os teores de MS; PB; EE; FDNcp; FDNi e Cinzas, conforme descrito anteriormente.

A excreção de matéria seca fecal foi estimada utilizando-se o indicador óxido crômico, sendo estimada com base na razão entre a quantidade do indicador fornecido e sua concentração nas fezes.

A estimativa do consumo individual de suplemento múltiplo pelas novilhas foi obtida através da seguinte equação:

$$
\text { CISup }=((\text { EFxCIFi }) / \text { IFG }) \times \text { SupFG }
$$

em que: CISup = consumo individual de suplemento $(\mathrm{kg} / \mathrm{dia}) ; \mathrm{EF}=$ excreção fecal em $\mathrm{kg} / \mathrm{dia} ; \mathrm{CIFi}=$ concentração do indicador nas fezes do animal $(\mathrm{kg} / \mathrm{kg}) ; \mathrm{IFG}=$ indicador presente no suplemento fornecido ao grupo $(\mathrm{kg} / \mathrm{dia})$; SupFG = quantidade de suplemento fornecida ao grupo de animais $(\mathrm{kg} /$ dia).

A estimação do consumo voluntário de matéria seca de forragem foi realizada empregando-se como indicador interno a FDN indigestível, conforme a equação:

$$
\text { CMS }(\mathrm{kg} / \mathrm{dia})=\{[(\text { EFxCIF })-\mathrm{IS}] / \mathrm{CIFO}\}+\mathrm{CMSS}
$$

em que: $\mathrm{CIF}=$ concentração do indicador nas fezes $(\mathrm{kg} / \mathrm{kg}) ; \mathrm{CIFO}=$ concentração do indicador na forragem $(\mathrm{kg} / \mathrm{kg})$; CMSS = consumo de matéria seca de suplemento (kg/dia); EF = excreção fecal ( $\mathrm{kg} / \mathrm{dia})$; e IS = consumo de indicador a partir do suplemento $(\mathrm{kg})$.
As análises de creatinina, ácido úrico e ureia foram realizadas no equipamento automático para bioquímica, marca Mindray, modelo: BS200E, utilizando-se kits de determinação da Bioclin.

A metodologia para a determinação do ácido úrico foi a enzimática colorimétrica, a partir da utilização de reagente enzimático, contendo: tampão, 4-aminoantipirina, azida sódica, peroxidase e uricase. A intensidade da cor cereja formada no cromógeno é diretamente proporcional à concentração de ácido úrico na amostra, que é medida no comprimento de onda $505 \mathrm{~nm}$ (490 - 540 $\mathrm{nm})$.

O método para a quantificação da ureia é o cinético de tempo fixo. Primeiramente a ureia é hidrolisada em amônia e dióxido de carbono pela urease. A seguir, a glutamato desidrogenase na presença de amônia e $\alpha$-cetoglutarato, oxida o NADH para NAD+. A oxidação de NADH a $\mathrm{NAD}+$, medida pela diminuição de absorbância é proporcional à concentração de ureia na amostra, que é lida espectrofotometricamente entre 334 $365 \mathrm{~nm}$.

A quantificação da creatinina foi realizada utilizando-se a metodologia cinética colorimétrica, onde a creatinina reage com o picrato alcalino em meio tamponado, obtendo-se um cromógeno cuja absorbância é proporcional à concentração de creatinina na amostra, medida no comprimento de onda de $510 \mathrm{~nm}$. Os cromógenos inespecíficos são eliminados por uma pré-leitura, pois estes têm formação imediata. O cálculo do volume urinário diário foi feito empregando-se a relação entre a excreção diária de creatinina (EC), adotando-se a equação proposta por Silva et al. (2012), e a sua concentração nas amostras "spot":

$$
\operatorname{ECU}(\mathrm{g} / \mathrm{dia})=0,0345 \times \mathrm{PCJ}^{0,9491}
$$

em que: $\mathrm{PCJ}=$ peso corporal em jejum.

As análises de alantoína foram feitas pelo método colorimétrico (CHEN; GOMES, 1992). A excreção total de derivados de purinas foi calculada 
pela soma das quantidades de alantoína e ácido úrico excretados na urina.

As purinas absorvidas (PA, mmol/dia) foram calculadas a partir da excreção de derivados de purinas (DP, mmol/dia), por intermédio da equação:

$$
P A=\frac{D P-0,301 \times P C^{0,75}}{0,80}
$$

em que: 0,80 é a recuperação de purinas absorvidas como derivados de purinas e $0,301 \times \mathrm{xC}^{0,75}$, a contribuição endógena para a excreção de purinas (BARBOSA et al., 2011).

A síntese ruminal de compostos nitrogenados (Y, g Nmic/dia) foi calculada em função das purinas absorvidas (X, mmol/dia), utilizando-se a equação descrita por Barbosa et al. (2011):

$$
N_{\text {mic }}=\frac{70 \times P A}{0,93 \times 0,137 \times 1000}
$$

em que: 70 é o conteúdo de $\mathrm{N}$ de purinas ( $\mathrm{mg} \mathrm{N} / \mathrm{mol}$ ); 0,137, a relação $\mathrm{N}$ purinas: $\mathrm{N}$ total nas bactérias; e 0,93 , a digestibilidade das purinas bacterianas.

\section{Análises estatísticas}

Utilizou-se o PROC GLM do SAS (Statistical Analysis System, versão 9.0) em todas as análises estatísticas. Para todos os procedimentos estatísticos foi adotado $\alpha=0,10$. As comparações entre as médias observadas foram realizadas por meio da decomposição da soma de quadrados para tratamentos em contrastes ortogonais relativos à comparação entre suplementação e nãosuplementação, e o efeito linear e quadrático para comparação entre os níveis de proteína bruta nos suplementos. Utilizou-se o peso corporal inicial como co-variável, quando este foi significativo.

\section{Resultados e Discussão}

Em um sistema de produção de gado de corte em que forragem representa a principal fonte de energia e nutrientes para os animais, é de suma importância que este apresente tanta qualidade quanto quantidade suficiente para atender os requisitos nutricionais dos animais. O conceito de MSpd contempla qualidade de forragem e deve ser segundo Paulino et al. (2008), fornecida na quantidade de 4 a $5 \%$ do peso corporal dos animais. Houve durante o período de realização desse experimento, a oferta de 4,65\% do peso vivo dos animais em MSpd, ou seja, havia disponibilidade adequada de forragem para os animais. O teor médio de PB da forragem foi de $5,8 \%$ (Tabela 2), sendo que $42,4 \%$ do nitrogênio presente na forragem durante o período experimental era de nitrogênio insolúvel em detergente neutro (NIDN). O valor de PB na forragem encontravase abaixo dos 7\% recomendado por Sampaio et al. (2009), como sendo o limite mínimo para que haja adequado aproveitamento da fibra em detergente neutro, principal fonte de energia para os bovinos criados em sistema de pastejo. $\mathrm{O}$ valor encontrado de PB na forragem apresentou-se abaixo do valor relatado por Lazzarini et. al. (2009), para que ocorra o consumo ótimo de forragem, que é de $10 \%$ de PB. Segundo Barros et al. (2014), forragem deficiente qualitativamente, prejudica a ocorrência de ganhos mais expressivos e mesmo com elevado consumo de suplemento, a baixa qualidade da forragem disponível limita o desempenho animal. 
Tabela 2. Composição química dos suplementos contendo 10\% $\left(\mathrm{PB}_{10}\right), 20 \%\left(\mathrm{~PB}_{20}\right), 30 \%\left(\mathrm{~PB}_{30}\right)$ e $40 \%$ de proteína bruta $\left(\mathrm{PB}_{40}\right)$ e da forragem.

\begin{tabular}{|c|c|c|c|c|c|c|}
\hline \multirow{2}{*}{ Item } & \multicolumn{4}{|c|}{ Suplementos } & \multirow[b]{2}{*}{ Forragem $^{5}$} & \multirow[b]{2}{*}{ Forragem $^{6}$} \\
\hline & $\mathrm{PB}_{10}$ & $\mathrm{~PB}_{20}$ & $\mathrm{~PB}_{30}$ & $\mathrm{~PB}_{40}$ & & \\
\hline Matéria Seca² & 94,8 & 94,5 & 94,1 & 93,7 & 38,2 & 39,3 \\
\hline Matéria Orgânica ${ }^{3}$ & 95,8 & 94,4 & 93,0 & 91,6 & 92,0 & 92,4 \\
\hline Proteína Bruta ${ }^{3}$ & 9,2 & 19,2 & 29,3 & 39,5 & 5,8 & 5,4 \\
\hline $\mathrm{NIDN}^{1,4}$ & 31,1 & 26,7 & 26,8 & 28,2 & 42,4 & 42,8 \\
\hline Extrato Etéreo ${ }^{3}$ & 1,47 & 1,14 & 0,82 & 0,55 & 0,9 & 1,12 \\
\hline $\mathrm{FDNcp}^{1,3}$ & 15,1 & 15,2 & 15,4 & 15,6 & 72,5 & 71,4 \\
\hline $\mathrm{CNF}^{1,3}$ & 70,0 & 58,86 & 47,48 & 35,95 & 12,8 & 14,4 \\
\hline $\mathrm{FDNi}^{1,3}$ & 2,24 & 2,06 & 1,87 & 1,68 & 34,6 & 33,3 \\
\hline
\end{tabular}

${ }^{1} \mathrm{NIDN}$ - nitrogênio insolúvel em detergente neutro; FDNcp - fibra em detergente neutro corrigida para cinzas e proteína; $\mathrm{CNF}$ Carboidratos não fibrosos; $\mathrm{FDNi}$ - fibra em detergente neutro indigestível. ${ }^{2} \mathrm{Em} \%$ de matéria natural. ${ }^{3} \mathrm{Em} \%$ de matéria seca. ${ }^{4} \mathrm{Em}$ $\%$ de nitrogênio total. ${ }^{5}$ Média das amostras obtidas por simulação manual do pastejo durante todo o período experimental. ${ }^{6}$ Média das amostras obtidas durante o ensaio para avaliação das características nutricionais.

Fonte: Elaboração dos autores.

Os animais suplementados apresentaram maior GMD e também maior PCF (Tabela 3), quando comparados aos não suplementados $(\mathrm{P}<0,10)$. Entre os animais suplementados com diferentes níveis de $\mathrm{PB}$, não houve diferença de GMD e nem de PCF $(\mathrm{P}<0,10)$, isso provavelmente ocorreu devido ao fato de que os animais consumindo o suplemento de mais baixo nível proteico, ter consumido uma dieta total de $6,8 \%$ de $\mathrm{PB}$, valor este próximo aos 7\% recomendado por Sampaio et al. (2009). Os animais suplementados apresentaram em média, 0,142 kg de GMD a mais do que os não suplementados e 15,55 $\mathrm{kg}$ a mais de PCF.

O melhor desempenho dos animais suplementados em relação aos do tratamento $\mathrm{MM}$, justifica-se pelo maior consumo de MS, MO, PB, CNF e NDT, ou seja, consumiram maior quantidade de alimento e também de nutrientes, em especial PB e NDT, que são determinantes no desempenho animal. O consumo de matéria seca é a variável mais importante que afeta o desempenho animal (WALDO; JORGENSEN, 1981), e por este ter sido maior para animais suplementados, é natural que estes apresentem maiores ganhos de peso. Entre os animais suplementados, observou-se diferença no consumo de PB. O consumo de PB teve efeito linear crescente, o que é explicado pela oferta crescente desse nutriente via suplementação.

Segundo Vaz, Lobato e Pascoal (2011), consumo de alimentos é regulado por fatores referentes ao animal (peso corporal, nível de produção), ao alimento (fibra, valor energético) e às condições de alimentação (disponibilidade). Além disso, os fatores ambientais aos quais o animal está exposto também podem afetar o consumo (NRC, 1996). O consumo de matéria seca em relação ao peso corporal (PC) dos animais não suplementados foi de $1,22 \%$ e para os animais suplementados foi de $1,5 \%$. Esses valores estão abaixo dos encontrados por Valente et al. (2011a) trabalhando com animais de mesma categoria, que foram: $1,7 \%$ para animais não suplementados e $2,5 \%$ para animais suplementados. Porém esses autores trabalharam também com animais mestiços com taurinos, os quais apresentam maior potencial de consumo de MS (FOX; SNIFFEN; O'CONNER, 1988). Outro fator que poderia ter atuação seria o fato de as novilhas utilizadas nesse trabalho, serem filhas de touros selecionados para a característica probabilidade de prenhez aos 14 meses (PP14). Animais sexualmente mais precoces apresentam deposição de gordura mais jovem, quando comparados a animais mais tardios, fato este que está relacionado ao controle de consumo. A característica PP14 pode apresentar 
correlação de $35 \%$ com a precocidade de acabamento de carcaça (FERRAZ; ELER, 2007). Os valores encontrados nesse trabalho para CMS (Tabela 4) estão bastante próximos dos valores sugeridos pelo BR-CORTE (2010), que seria de 3,02 kg para os animais não suplementados e de $3,93 \mathrm{~kg}$ para os animais suplementados.

Tabela 3. Médias, coeficientes de variação e indicativos de significância para peso corporal inicial (PCI), peso corporal final (PCF) e ganho médio diário (GMD) em novilhas suplementados e não suplementadas.

\begin{tabular}{|c|c|c|c|c|c|c|c|c|c|}
\hline \multirow[b]{2}{*}{ Item } & \multicolumn{5}{|c|}{ Suplementos $^{3}$} & \multirow{2}{*}{$\begin{array}{c}\text { Coeficiente de } \\
\text { variação (\%) }\end{array}$} & \multicolumn{3}{|c|}{ Valor $-\mathrm{P}^{1}$} \\
\hline & $\mathrm{MM}$ & $\mathrm{PB}_{10}$ & $\mathrm{~PB}_{20}$ & $\mathrm{~PB}_{30}$ & $\mathrm{~PB}_{40}$ & & $\mathrm{CO}$ & $\mathrm{L}$ & Q \\
\hline $\mathrm{PCI}^{2}$ & 231,4 & 232,6 & 230,8 & 231,8 & 231,6 & & & & \\
\hline $\mathrm{PCF}^{2}$ & 241,1 & 257,5 & 256,6 & 253,5 & 259,0 & 3,28 & $<, 0001$ & 0,8073 & 0,4373 \\
\hline GMD $^{2}$ & 0,091 & 0,232 & 0,242 & 0,203 & 0,256 & 33,54 & $<, 0001$ & 0,8006 & 0,4442 \\
\hline
\end{tabular}

${ }^{1}$ Indicativos de significância para contraste (CO) entre animais suplementados e não suplementados e para efeito de ordem linear (L) e quadrática (Q) do nível de proteína bruta nos suplementos. ${ }^{2}$ em $\mathrm{kg} .{ }^{3}$ mistura mineral (MM), suplementos com $10 \%\left(\mathrm{~PB}{ }_{10}\right)$, $20 \%\left(\mathrm{~PB}_{20}\right), 30 \%\left(\mathrm{~PB}_{30}\right)$ e $40 \%$ de proteína bruta $\left(\mathrm{PB}_{40}\right)$.

Fonte: Elaboração dos autores.

Tabela 4. Médias, coeficientes de variação e indicativos de significância para o consumo em novilhas sob pastejo recebendo ou não suplementos com diferentes níveis de proteína bruta $(\mathrm{kg})$.

\begin{tabular}{|c|c|c|c|c|c|c|c|c|c|}
\hline \multirow{2}{*}{ Item } & \multicolumn{5}{|c|}{ Suplementos $^{4}$} & \multirow{2}{*}{$\begin{array}{l}\text { Coeficiente de } \\
\text { variação (\%) }\end{array}$} & \multicolumn{3}{|c|}{ Valor $-\mathrm{P}^{2}$} \\
\hline & MM & $\mathrm{PB}_{10}$ & $\mathrm{~PB}_{20}$ & $\mathrm{~PB}_{30}$ & $\mathrm{~PB}_{40}$ & & $\mathrm{CO}$ & $\mathrm{L}$ & $\mathrm{Q}$ \\
\hline Matéria seca de suplemento & 0,00 & 0,88 & 0,89 & 0,88 & 0,89 & --- & $\begin{array}{l}-- \\
--\end{array}$ & --- & --- \\
\hline Matéria seca & 3,02 & 3,84 & 4,02 & 3,46 & 3,52 & 25,80 & 0,0211 & 0,2791 & 0,7622 \\
\hline Matéria seca de forragem & 3,02 & 2,96 & 3,13 & 2,58 & 2,63 & 29,31 & 0,5152 & 0,2532 & 0,8150 \\
\hline Matéria orgânica & 2,75 & 3,53 & 3,70 & 3,20 & 3,24 & 25,80 & 0,0144 & 0,2384 & 0,7880 \\
\hline $\begin{array}{l}\text { Matéria orgânica de } \\
\text { forragem }\end{array}$ & 2,75 & 2,74 & 2,88 & 2,38 & 2,43 & 29,32 & 0,6216 & 0,2521 & 0,8469 \\
\hline Proteína Bruta ${ }^{3}$ & 0,18 & 0,26 & 0,39 & 0,43 & 0,55 & 23,78 & $<, 0001$ & $<, 0001$ & 0,9391 \\
\hline $\mathrm{FDNcp}^{1}$ & 2,14 & 2,32 & 2,36 & 2,01 & 2,04 & 28,05 & 0,8558 & 0,2349 & 0,9485 \\
\hline Matéria seca digerida & 1,45 & 2,20 & 2,33 & 2,12 & 2,07 & 28,03 & 0,0026 & 0,5720 & 0,6471 \\
\hline $\mathrm{FDND}^{1}$ & 1,22 & 1,37 & 1,29 & 1,19 & 1,17 & 27,99 & 0,8065 & 0,2339 & 0,8003 \\
\hline Nutrientes digestíveis totais & 1,42 & 2,29 & 2,30 & 2,08 & 2,03 & 25,17 & 0,0007 & 0,2794 & 0,8340 \\
\hline & & & & & & $\mathrm{g} / \mathrm{kg}$ de $\mathrm{PC}$ & & & \\
\hline Matéria seca & 12,24 & 15,55 & 16,49 & 14,35 & 13,96 & 24,59 & 0,0426 & 0,2467 & 0,6201 \\
\hline Matéria seca de forragem & 12,24 & 11,37 & 12,09 & 10,18 & 9,99 & 29,01 & 0,2598 & 0,2358 & 0,6892 \\
\hline $\mathrm{FDNcp}^{1}$ & 8,68 & 8,92 & 9,11 & 7,96 & 7,75 & 27,48 & 0,7793 & 0,2146 & 0,8142 \\
\hline
\end{tabular}

${ }^{1}$ FDNcp: Fibra em detergente neutro corrigida para cinzas e proteínas. FDND: Fibra em detergente neutro digerida. ${ }^{2}$ Indicativos de significância para contraste $(\mathrm{CO})$ entre animais suplementados e não suplementados e para efeito de ordem linear (L) e quadrática (Q) do nível de proteína bruta nos suplementos. ${ }^{3} \hat{Y}=0,1790+0,0092 x\left(\mathrm{r}^{2}=0,6032\right) .{ }^{4}$ mistura mineral (MM), suplementos com $10 \%$ $\left(\mathrm{PB}_{10}\right), 20 \%\left(\mathrm{~PB}_{20}\right), 30 \%\left(\mathrm{~PB}_{30}\right)$ e $40 \%$ de proteína bruta $\left(\mathrm{PB}_{40}\right)$.

Fonte: Elaboração dos autores. 
Houve maior digestibilidade de MS, MO e $\mathrm{PB}$, proporcionando maiores teores de NDT para os animais suplementados em relação aos não suplementados (Tabela 5). Isso se deve à inclusão de suplemento na dieta dos animais, uma vez que um aumento na digestibilidade total pode ser esperado com a inclusão de concentrados na dieta porque eles, usualmente, apresentam digestibilidade maiores do que o pasto (PAULINO et al., 2008), e também devido a maior concentração destes componentes nos suplementos, o que incrementa sua participação na dieta total, reduzindo a participação relativa da fração metabólica fecal (VAN SOEST, 1994). Entre os animais suplementados com diferentes níveis de $\mathrm{PB}$, ocorreram diferenças na digestibilidade da PB, apresentando efeito quadrático. Segundo Cameron et al. (1991), a digestibilidade da PB aumenta com o teor de PB do alimento, que foi o que ocorreu nesse estudo.

Tabela 5. Médias, Coeficientes de variação e indicativos de significância para os coeficientes de digestibilidade (\%) aparente total dos componentes da dieta em novilhas suplementadas e não suplementadas.

\begin{tabular}{|c|c|c|c|c|c|c|c|c|c|}
\hline \multirow{2}{*}{ Item } & \multicolumn{5}{|c|}{ Suplementos ${ }^{4}$} & \multirow{2}{*}{$\begin{array}{c}\text { Coeficiente de } \\
\text { variação(\%) }\end{array}$} & \multicolumn{3}{|c|}{ Valor $-\mathrm{P}^{2}$} \\
\hline & $\mathrm{MM}$ & $\mathrm{PB}_{10}$ & $\mathrm{~PB}_{20}$ & $\mathrm{~PB}_{30}$ & $\mathrm{~PB}_{40}$ & & $\mathrm{CO}$ & $\mathrm{L}$ & Q \\
\hline Matéria seca & 47,77 & 50,16 & 54,72 & 58,46 & 56,43 & 17,52 & 0,0470 & 0,1448 & 0,3266 \\
\hline Matéria orgânica & 51,21 & 53,87 & 57,81 & 61,19 & 59,28 & 15,22 & 0,0416 & 0,1660 & 0,3422 \\
\hline Proteína Bruta ${ }^{3}$ & 23,83 & 32,56 & 47,89 & 61,52 & 68,64 & 8,90 & $<, 0001$ & $<, 0001$ & 0,0192 \\
\hline $\mathrm{FDNcp}^{1}$ & 56,93 & 59,29 & 54,67 & 58,77 & 57,87 & 9,48 & 0,7089 & 0,9847 & 0,3443 \\
\hline $\begin{array}{c}\text { Nutrientes } \\
\text { degestíveis totais }\end{array}$ & 46,86 & 56,48 & 54,08 & 57,37 & 55,38 & 7,66 & $<, 0001$ & 0,9991 & 0,8938 \\
\hline
\end{tabular}

${ }^{1}$ FDNcp: Fibra em detergente neutro corrigida para cinzas e proteínas. ${ }^{2}$ Indicativos de significância para contraste $(\mathrm{CO})$ entre animais suplementados e não suplementados e para efeito de ordem linear (L) e quadrática (Q) do nível de proteína bruta nos suplementos. ${ }^{3} \hat{\mathrm{Y}}=11,9122+2,2460 \mathrm{x}-0,0205 \mathrm{x}^{2}\left(\mathrm{r}^{2}=0,9051\right) .{ }^{4}$ mistura mineral $(\mathrm{MM})$, suplementos com $10 \%\left(\mathrm{~PB}_{10}\right), 20 \%\left(\mathrm{~PB}_{20}\right)$, $30 \%\left(\mathrm{~PB}_{30}\right)$ e $40 \%$ de proteína bruta $\left(\mathrm{PB}_{40}\right)$.

Fonte: Elaboração dos autores.

Nesse trabalho não foi observado aumento na digestibilidade e nem no consumo da FDNcp, isso quando se comparou animais suplementados ou não suplementados e também entre os animais suplementados com níveis crescentes de PB. Este resultado foi semelhante ao de Valente et al. (2011a), que também não observaram efeito da suplementação sobre a digestibilidade da fração fibrosa da dieta, trabalhando com novilhas na época seca. Isso pode ter ocorrido devido ao alto teor de FDNi (33,3\%), presente na forragem (Tabela 2). Por outro lado, segundo Detmann et al. (2014), a ocorrência de um efeito positivo da suplementação proteica é devido à atenuação da carência geral de nitrogênio no rúmen. Este tipo de deficiência restringe a disponibilidade de precursores de nitrogênio para a síntese de enzimas fibrolíticos.
Os animais suplementados apresentaram maior produção de nitrogênio microbiano (Nmic), maior presença de nitrogênio uréico no soro (NUS) e também maior relação nitrogênio ureico na urina/ nitrogênio da creatinina (NUU/Ncre), não diferindo dos não suplementados quanto a eficiência de produção microbiana (Emic). É de conhecimento geral que existe uma relação simbiótica entre ruminantes e microorganismos, onde os animais ruminantes fornecem aos microorganismos um ambiente adequado para seu crescimento e multiplicação, além de suprimento contínuo de substrato. Por outro lado essa microbiota permite que os ruminantes utilizem carboidratos estruturais e também o nitrogênio não proteico (SOUZA; PEIXOTO; TOLEDO, 2002). O crescimento microbiano é afetado pela disponibilidade de 
nutrientes exigidos pelos microrganismos ruminais, como carboidratos, amônia, peptídeos, aminoácidos, enxofre e ácidos graxos de cadeia ramificada (VAN SOEST, 1994). Assim sendo, pode-se atribuir a maior produção microbiana encontrada aos animais suplementados, pelo fato de que todos os nutrientes foram consumidos em maior quantidade por eles, com exceção da FDNcp.

A maior presença de NUS e NUU/Ncre (Tabela 6) para animais suplementados em relação ao tratamento controle já era esperada, uma vez que eles apresentaram maiores consumos de PB, consequentemente, de nitrogênio. Os valores foram: 7 e $12,9 \mathrm{mg} / \mathrm{dL}$ de NUS em animais suplementados e não suplementados, respectivamente, e 13,06 e 5,35 g/dia de NUU/Ncre, em animais suplementados e não suplementados, respectivamente. Não foi observada diferença na Emic entre animais suplementados ou não. Embora a síntese microbiana tenha sido significativamente maior em animais suplementados, os animais sem suplementação consumiram significativamente menor quantidade de NDT, o que permitiu que a Emic fosse igual em ambos os grupos.
Entre os animais que receberam diferentes níveis de PB foram identificadas diferenças na produção de Nmic, na Emic, na presença de NUU/Ncre e NUS (Tabela 6). Todos os parâmetros apresentaram efeito quadrático com o aumento dos níveis de PB. A maior produção de Nmic foi para o nível $26,6 \%$ de $\mathrm{PB}$, provavelmente pela melhor relação proteína:energia nesse nível. A maior Emic ocorreu para o nível 28,3\% de PB. Valadares et al. (1997) sugeriram que os níveis de N-uréia plasmáticas entre 13,52 e $15,15 \mathrm{mg} / \mathrm{dL}$ correspondem à máxima eficiência microbiana e provavelmente seria o limite no qual ocorre perda de proteína em novilhos zebuínos alimentados com $62,5 \%$ de NDT. A quantidade de NUS em animais consumindo 28,3\% (maior Emic) de PB seria 13,5 mg/dL, o que corrobora com os valores relatados por Valadares et al. (1997). Os valores de NUS e NUU/Ncre tiveram comportamento semelhante e aumentaram com o aumento dos níveis de PB fornecidos via suplementação, mostrando que com o aumento do consumo de proteína houve também o aumento de sua excreção.

Tabela 6. Médias, desvio padrão e indicativos de significância para produção de nitrogênio microbiano (Nmic), eficiência microbiana em relação aos nutrientes digestíveis totais (Emic), nitrogênio uréico no soro (NUP) e relação nitrogênio ureico na urina/nitrogênio da creatinina (NUU/Ncre) em novilhas suplementados e não suplementadas.

\begin{tabular}{|c|c|c|c|c|c|c|c|c|c|}
\hline \multirow[b]{2}{*}{ Item } & \multicolumn{5}{|c|}{ Suplementos } & \multirow{2}{*}{$\begin{array}{c}\text { Coeficiente de variação } \\
(\%)\end{array}$} & \multicolumn{3}{|c|}{ Valor $-\mathrm{P}^{1}$} \\
\hline & MM & $\mathrm{PB}_{10}$ & $\mathrm{~PB}_{20}$ & $\mathrm{~PB}_{30}$ & $\mathrm{~PB}_{40}$ & & $\mathrm{CO}$ & $\mathrm{L}$ & Q \\
\hline $\mathrm{Nmic}^{2,5}$ & 34,52 & 28,97 & 54,08 & 48,51 & 39,82 & 25,43 & 0,0549 & $<, 0001$ & 0,0001 \\
\hline Emic $^{3,6}$ & 152,18 & 93,65 & 149,36 & 139,63 & 131,99 & 28,79 & 0,1227 & 0,0131 & 0,0247 \\
\hline NUS ${ }^{4,7}$ & 7,00 & 6,36 & 8,69 & 15,11 & 21,58 & 12,66 & $<, 0001$ & 0,9827 & 0,0012 \\
\hline NUU/Ncre ${ }^{8}$ & 5,35 & 3,97 & 7,14 & 15,45 & 25,68 & 18,86 & $<, 0001$ & 0,5086 & 0,0003 \\
\hline
\end{tabular}

${ }^{1}$ Indicativos de significância para contraste $(\mathrm{CO})$ entre animais suplementados e não suplementados e para efeito de ordem linear (L) e quadrática (Q) do nível de proteína bruta nos suplementos. ${ }^{2} \mathrm{em} \mathrm{g} / \mathrm{dia} .{ }^{3} \mathrm{em} \mathrm{g} \mathrm{PB} \mathrm{microbiana/Kg} \mathrm{de} \mathrm{nutrientes} \mathrm{digestíveis}$ totais. ${ }^{4} \mathrm{em} \mathrm{mg} / \mathrm{dl}$ de soro. ${ }^{5} \hat{\mathrm{Y}}=-6,1484+4,4952 \mathrm{x}-0,0845 \mathrm{x}^{2}\left(\mathrm{R}^{2}=0,4281\right) .{ }^{6} \hat{\mathrm{Y}}=24,9755+8,8130 \mathrm{x}-0,1555 \mathrm{x}^{2}\left(\mathrm{R}^{2}=0,3593\right) .{ }^{7}$ $\hat{\mathrm{Y}}=5,0899+0,0032 \mathrm{x}+0,0104 \mathrm{x}^{2}\left(\mathrm{R}^{2}=0,9351\right) .{ }^{8} \hat{\mathrm{Y}}=3,5231-0,1480 \mathrm{x}+0,0176 \mathrm{x}^{2}\left(\mathrm{R}^{2}=0,9277\right)$.

Fonte: Elaboração dos autores. 


\section{Conclusão}

O fornecimento de suplementação múltipla para novilhas Nelore sexualmente precoces durante a recria, na época seca do ano, proporciona maiores ganhos de peso e peso corporal, independente dos níveis proteicos dos suplementos testados.

\section{Referências}

BARBOSA, A. M.; VALADARES, R. F. D.; VALADARES FILHO, S. C.; PINA, D. S.; DETMANN, E.; LEÃO, M. I. Endogenous fraction and urinary recovery of purine derivatives obtained by different methods in Nellore cattle. Journal of Animal Science, Champaign, v. 89, n. 2, p. 510-519, 2011.

BARROS, L. V.; PAULINO, M. F.; MORAES, E. H. B. K.; DETMANN, E.; ALMEIDA, D. M.; MARTINS, L. S.; SILVA, A. G.; LOPES, S. A.; MÁRQUEZ, D. E. C.; CARDENAS, J. E. G. Desempenho produtivo e nutricional de novilhas de corte em pastejo suplementadas no período da seca e/ou no período de transição seca águas. Semina: Ciências Agrárias, Londrina, v. 35, n. 4, p. 2655-2672, 2014. Suplemento 1.

BR-CORTE - Exigências nutricionais de zebuínos puros e cruzados. 2. ed. Viçosa: UFV, Suprema Gráfica Ltda., 2010. 193 p.

CAMERON, M. R.; KLUSMEYER, T. H.; LYNCH, G. L.; CLARK, J. H.; NELSON, D. R. Effects of urea and starch on rumen fermentation, nutrient passage to the duodenum, and performance of cows. Journal of Dairy Science, Champaign, v. 74, n. 4, p. 1321-1336, 1991.

CHEN, X. B.; GOMES, M. J. Estimation of microbial protein supply to sheep and cattle basid on urinary excretion of purine derivatives - an overview of the technical details. International Feed Resources Unit, Rowett Research Institute, Ocasional Publication; Ed. Buchsburnd Aberdeen, UK: 1992. 22 p.

DETMANN, E.; PAULINO, M. F.; MANTOVANI, H. C.; VALADARES FILHO, S. C.; SAMPAIO, C. B.; SOUZA, M. A.; LAZZARINI, I.; DETMANN, K. S. C. Parameterization of ruminal fibre degradation in lowquality tropical forage using Michaelis-Menten kinetics. Livestock Science, v. 126, n. 1-3, p. 136-146, 2009.

DETMANN, E.; PAULINO, M. F.; VALADARES FILHO, S. C. Otimização do uso de recursos forrageiros basais. In: SIMPÓSIO DE PRODUÇÃO DE GADO DE CORTE, 7., 2010, Viçosa. Anais...Viçosa: SIMCORTE, 2010. p. 191-240.
DETMANN, E.; PAULINO, M. F.; VALADARES FILHO, S. C.; HUHTANEN, P. Nutritional aspects applied to grazing cattle in the tropics: a review based on Brazilian results. Semina: Ciências Agrárias, Londrina, v. 35 , n. 4, p. 2829-2854, 2014. Supplement 1.

DETMANN, E.; PAULINO, M. F.; ZERVOUDAKIS, J. T.; VALADARES FILHO, S. C.; EUCLIDES, R. F.; LANA, R. P.; QUEIRÓZ, D. S. Cromo e Indicadores internos na determinação do Consumo de novilhos mestiços, suplementados, a pasto. Revista Brasileira de Zootecnia, Viçosa, MG, v. 30, n. 5, p. 1600-1609, 2001.

ELER, J. P.; SILVA, J. A. V.; FERRAZ, J. B. S.; DIAS, F.; OLIVEIRA, H. N.; EVANS, J. L.; GOLDEN, B. L. Genetic evaluation of the probability of pregnancy at 14 months for Nellore heifers. Journal of Animal Science, Champaign, v. 80, n. 4, p. 951-954, 2002.

FOOD AND AGRICULTURE ORGANIZATION - FAO. 2005. Available at: <http://faostat. fao.org>. Accessed at: 13 maio 2013.

FERRAZ, J. B. S.; ELER, J. P. Seleção de Bos indicus para precocidade sexual. Revista Brasileira de Reprodução Animal, Belo Horizonte, v. 31, n. 2, p. 167-171, 2007. Disponível em: $<$ http://www.cbra.org.br>. Acesso em: 14 maio 2013.

FOX, D. G.; SNIFFEN, C. J.; O'CONNER, J. D. Adjusting nutrient of beef cattle for animal and environmental variations. Journal of Animal Science, Champaign, v. 66, n. 6, p. 1475-1495, 1988.

LAZZARINI, I.; DETMANN, E.; SAMPAIO, C. B.; PAULINO, M. F.; VALADARES FILHO, S. C.; SOUZA, M. A.; OLIVEIRA, F. A. Dinâmicas de trânsito e degradação da fibra em detergente neutro em bovinos alimentados com forragem tropical de baixa qualidade e compostos nitrogenados. Arquivo Brasileiro de Medicina Veterinária e Zootecnia, Belo Horizonte, v. 61, n. 3, p. 635-647, 2009.

MERTENS, D. R. Gravimetric determination of amylasetreated neutral detergent fiber in feeds with refluxing in beaker or crucibles: collaborative study. Journal of AOAC International, Rockville, v. 85, n. 6, p. 1217-1240, 2002.

NATIONAL RESEARCH COUNCIL - NRC. Nutrient requeriment of beef cattle. Washington D. C.: National Academy Press, 1996. 244 p.

PAULINO, P. V. R.; VALADARES FILHO, S. C.; DETMANN, E.; VALADARES, R. F. D.; FONSECA, M. A.; VÉRAS, R. M. L.; OLIVEIRA, D. M. Desempenho produtivo de bovinos Nelore de diferentes classes sexuais alimentados com dietas contendo dois níveis de oferta de concentrados. Revista Brasileira de Zootecnia, Viçosa, MG, v. 37, n. 6, p. 1079-1087, 2008. 
SAMPAIO, C. B.; DETMANN, E.; LAZZARINI, I.; SOUZA, M. A.; PAULINO, M. F.; VALADARES FILHO, S. C. Rumen dynamics of neutral detergent fiber in cattle fed low-quality tropical forage and supplemented with nitrogenous compounds. Revista Brasileira de Zootecnia, Viçosa, MG, v. 38, n. 3, p. 560-569, 2009.

SILVA, D. J.; QUEIROZ, A. C. Análise de alimentos: métodos químicos e biológicos. 3. ed. Viçosa: UFV, Imp. Univ., 2002. 165 p.

SILVA, L. F. C.; VALADARES FILHO, S. C.; CHIZZOTTI, M. L.; ROTTA, P. P.; PRADOS, L. F.; VALADARES, R. F. D.; ZANETTI, D.; BRAGA, J. M. S. Creatinine excretion and relationship with body weight of Nellore cattle. Revista Brasileira de Zootecnia, Viçosa, MG, v. 41, n. 3, p. 807-810, 2012.

SOUZA, J. S. I.; PEIXOTO, A. M.; TOLEDO, F. F. de. Enciclopédia agrícola brasileira. São Paulo: Editora da Universidade de São Paulo, v. 4, 2002. 607 p.

TITGEMEYER, E. C.; ARMENDARIZ, C. K.; BINDEL, D. J.; GREENWOOD, R. H.; LOEST, C. A. Evaluation of titanium dioxide as a digestibility marker for cattle. Journal of Animal Science, Champaign, v. 79, n. 4, p. 1059-1063, 2001.

VALADARES, R. F. D.; GONÇALVES, L. C.; RODRIGUEZ, N. M.; VALADARES FILHO, S. C.; SILVA, J. F. C. Níveis de proteína em dietas de bovinos. 2. Consumo, digestibilidade e balanço de compostos nitrogenados. Revista Brasileira de Zootecnia, Viçosa, MG, v. 26, n. 6, p. 1259-1263, 1997.

VALENTE, E. E. L.; PAULINO, M. F.; DETMANN, E.; VALADARES FILHO, S. C.; BARROS, L. V.; ACEDO, T. S.; COUTO, V. R. M.; LOPES, S. A. Levels of multiple supplements or nitrogen salt for beef heifers in pasture during the dry season. Revista Brasileira de Zootecnia, Viçosa, MG, v. 40, n. 9, p. 2011-2019, 2011a.
VALENTE, T. N. P.; DETMANN, E.; QUEIROZ, A. C.; VALADARES FILHO, S. C.; GOMES, D. I.; FIGUEIRAS, J. F. Evaluation of rumen degradation profiles of forages using bags made from different textiles. Revista Brasileira de Zootecnia, Viçosa, MG, v. 40, n. 11, p. 2565-2573, 2011 b.

VAN SOEST, P. J. Nutritional ecology of the ruminant. $2^{\text {th }}$ ed. Ithaca: Cornell University Press, 1994. 476 p.

VAN SOEST, P. J.; ROBERTSON, J. B. Analysis of forages and fibrous foods. Ithaca: Cornell University, 1985. $202 \mathrm{p}$.

VAZ, R. Z.; LOBATO, J. F. P.; PASCOAL, L. L. Desenvolvimento de bezerros de corte desmamados aos 80 ou 152 dias até os 15-16 meses de idade. Revista Brasileira de Zootecnia, Viçosa, MG, v. 40, n. 1, p. 221229, 2011.

WALDO, D. R.; JORGENSEN, N. A. Forages for high animal production: Nutritional factors and effects of conservation. Journal of Dairy Science, Champaign, v. 64, n. 6, p. 1207-1229, 1981.

WEISS, W. P. Energy prediction equations for ruminant feeds. In: CORNELL NUTRITION CONFERENCE FOR FEED MANUFACTURERS, 61., 1999, Ithaca. Proceedings... Ithaca: Cornell University, 1999. p. 176185.

WILLIANS, C. H.; DAVID, D. J.; IISMA, O. The determination of chromic oxide in faeces samples by atomic absorption spectrophotometry. Journal of Agricultural Science, Toronto, v. 59, n. 3, p. 381-385, 1962. 